\title{
Subsidy Policy Assessment of Renewable Energy Grid-connected Externalities
}

\author{
Cai Qiang ${ }^{1,2}$, Gao Yuanpan ${ }^{2}$ \\ ${ }^{1}$ School of Economics Management, Sichuan Radio TV University, Chengdu, China \\ ${ }^{2}$ School of Management and Economics, University of Electronic Science and Technology of \\ China, Chengdu, China
}

\begin{abstract}
According to the current conditions of renewable energy power industry, the article deals with the positive and negative externalities of renewable energy grid connection, summarizes the solutions to renewable energy grid connection externalities, analyzes the incentive policies of the current Chinese renewable energy power industry, puts focus on generation technology, subsidy, taxation, assesses the effectiveness of incentive policies of the current Chinese renewable energy power industry, points out the incompleteness of subsidy and taxation in the grid connection development of renewable energy and power and inflexibility in feed-in tariff formation, and offers countermeasures for those problems.
\end{abstract}

Key words:renewable energy and power, grid connection, subsidy policies

\section{基于可再生能源发电并网外部性的补贴政策评价}

\author{
蔡强 $^{1,2}$, 高远攀 ${ }^{2}$ \\ 1 四川广播电视大学经济管理学院 \\ 2 电子科技大学经济与管理学院
}

中文摘要：基于可再生能源电力产业现状, 展开对可再生能源发电并网正负外部性的分 析, 总结可再生能源发电并网外部性的解决 办法。梳理我国现行的可再生能源电力行业 激励政策，重点从发电技术、补贴、税收等 视角分析、评价可再生能源电力现行激励政 策的有效性, 指出我国在可再生能源电力并
网发展中存在补贴和税收机制不完善，补贴 不足，上网电价形成机制缺乏灵活性等问题， 并给出相应的对策措施。

关键词: 可再生能源电力; 发电并网; 补 贴政策 


\section{1 引言}

随着产业规模的不断扩大，我国可再生 能源开发面临的诸多问题和障碍逐渐显现, 成为制约我国可再生能源产业规模化的瓶 颈，如成本居高不下、自主创新能力较弱、 制造和配套能力急待提升、关键零部件国产 率低、政出多门、行业管理松散、标准体系 建设严重滞后、政策措施的出台滞后于产业 发展的客观需求等, 而并网难则成为当前可 再生能源发电的最大瓶颈。然而, 并网难问 题并不只是以上原因的产物, 可再生能源电 力本身的负外部性也是其中的重要原因之

针对可再生能源电力外部性以及上网难 问题, 我国采取了补贴政策, 目前的可再生 能源电力上网补贴政策主要依据《可再生能 源法》、《可再生能源电价附加补助资金管理 暂行办法》等制定。然而补贴政策对刺激我 国可再生能源电力投资的效果有待进一步论 证, 相关理论研究尚需不断创新和发展。

赵子健、赵旭（2012）指出 2010 年中国 的可再生能源比例未达预期目标, 同时部分 可再生能源电力却由于无法上网外送而浪 费，原因在于目前的政策设计没有考虑电网 的非线性投入产出关系, 从而激励政策效果 有限 ${ }^{[1]}$ 。杨帅（2013）对我国可再生能源补 贴政策作了福利效应分析, 通过测算开发平 均成本、产业成本负担和生活消费负担, 指 出我国可再生能源补贴政策对不同产业和居 民的福利影响虽然较小, 但存在不公平分担 的问题 ${ }^{[2]}$ 。谢旭轩、王仲颖、高虎（2013） 总结了具有国际可再生能源发展领先水平的 代表性国家的可再生能源补贴政策机制及其 最新动向, 提出了针对我国目前面临的可再 生能源补贴资金不足问题的一些建议 ${ }^{[3]}$ 。汪 芗（2012）站在立法角度, 通过系统梳理我 国已颁布的可再生能源法律法规及政策, 对 我国可再生能源产业财政补贴制度提出了建 议 ${ }^{[4]}$ 。柯建飞（2006）从可再生能源发展基 金的设立、税收支持、财政补贴和可再生能 源电力价格保护等四个方面作了探讨 ${ }^{[5]}$ 。赵 寒娇（2009）分析了可再生能源电力的制约 因素、政策缺陷, 提出建立我国可再生能源 电力产业发展激励机制的建议 ${ }^{[6]}$ 。
国外文献方面, Hüseyin Benli(2013)研究 了在土耳其可再生能源资源目前的潜力和在 国家能源消耗的贡献的大小 ${ }^{[7]}$ 。Cheuk Wing Lee 和 Jin Zhong（2014）从可再生能源的全 球市场领导者和趋势进行识别和分析, 提出 了最有前景的可再生能源的投资工具供投资 者参考 ${ }^{[8]}{ }_{0}$ Florian Kern 和 Adrian $\operatorname{Smith}(2014$ ) 指出英国的海上风电部署在世界出于领先地 位, 这种领先地位来源于英国可再生能源的 激励政策 ${ }^{[9]}$ 。Durmus Kaya（2005）探讨了土 耳其可再生能源政策和塑造这些政策的政治 组织, 并从有效利用可再生能源的潜力、能 源政治、政治组织、激励、定价和购买机制 等方面进行分析并给出解决这些问题的提案 和建议 ${ }^{[10]}$ 。Ryan Wiser, Steven Pickle 和 Charles Goldman（1998）分析了加州规定范 围内产业调整可再生能源的支持方案的设计 的案例, 得到了来自加州的经验 ${ }^{[11]}$ 。

本文运用外部性理论重点分析了可再生 能源电力的外部性, 由目前对外部性的解决 方法延伸梳理了我国可再生能源现行电力上 网政策（Feed-in Tariff）及其政策制定背景, 重点展开对可再生能源电力上网补贴机制、 税收机制、电价形成机制的分析和评价，并 指出所存在的问题和相应的对策措施。

\section{2 可再生能源电力外部性}

外部性又称为溢出效应、外部影响或外 差效应, 指一个人或一群人的行动和决策使 另一个人或一群人受损或受益的情况, 分为 正外部性 (positive externality) 和负外部性 (negative externality)。正外部性是某个经济行 为个体的活动使他人或社会受益, 而受益者 无须花费代价, 负外部性是某个经济行为个 体的活动使他人或社会受损，而造成负外部 性的人却没有为此承担成本。下面将对可再 生能源电力这种典型公共产品的正负外部性 分别进行分析。

\section{1 可再生能源电力正外部性}

就社会经济效益方面而言, 对可再生能 源投资的增加, 直接增加社会投资, 从而促 进经济增长, 增加就业机会, 提高能源安全。 从环境方面看, 可再生能源的节能减排效益 明显高于传统发电方式。成本方面, 以风能 为例, 根据国家发改委价格司发布的《关于 
完善风力发电上网电价政策的通知》, 按风能 资源状况和工程建设条件, 将全国分为四类 风资源区, 成本电价如下表 1 所示。由于风 力发电整个过程不会产生环境污染物, 因此 不计环境成本。

表 1 风电平均成本电价

$\begin{array}{lcc}\text { 成本电价 } & \text { 占国土面积比 } & \text { 完全成本 } \\ \begin{array}{l}\text { (元/千 } \\ \text { 瓦时 }\end{array} & \text { 例 } & \text { (元/千瓦 } \\ & & \text { 时) }\end{array}$

\begin{tabular}{llll}
\hline $\begin{array}{l}\text { 风资源丰 } \\
\text { 富区 }\end{array}$ & 0.51 & $8 \%$ & \\
\hline 风资源较丰富区 & 0.54 & $18 \%$ & 0.5744 \\
\hline $\begin{array}{l}\text { 风资源可利用区 } \\
\text { 风资源贫乏区 }\end{array}$ & 0.58 & $50 \%$ & \\
\hline
\end{tabular}

数据来源: 国家统计局, 国家发改委, 北极星电力网

如果将风电与我国现行发电量占比最大 的火电相比, 风电在环境成本上占据极大优 势。下表 2 为燃煤火电完全成本表。

表 2 燃煤火电完全成本

$\begin{array}{cccc}\text { 污染物及其他 } & \text { 环境成 } & \text { 成本电价 } & \text { 完全成本 } \\ \text { 成本项目 } & \text { 本 (元/ } & \text { （元/千瓦 } & \text { (元/千瓦 } \\ & \text { 千瓦时) } & \text { 时) } & \text { 时) }\end{array}$

\begin{tabular}{llll}
\hline $\mathbf{S O}_{\mathbf{2}}$ & 0.1795 & & \\
$\mathbf{N} \mathbf{O}_{\mathbf{x}}$ & 0.0366 & & \\
$\mathbf{C O}_{\mathbf{2}}$ & 0.1865 & 0.4752 & 1.0302 \\
$\mathbf{P M 2 . 5}$ & 0.1065 & & \\
煤炭开采 & 0.0423 & & \\
煤炭运输 & 0.0036 \\
合计 & 0.5550 & \\
\hline
\end{tabular}

数据来源: 国家统计局, 国家发改委, 北极星电力网

从表 1 、表 2 对比分析可以看出, 风电 发电的完全成本远低于燃煤火电完全成本,
特别在环境成本方面, 凸显风电的优势。其 他可再生能源发电在环境成本方面, 同样优 于燃煤发电, 可再生能源发电正外部性得以 显现。

\section{2 可再生能源电力负外部性}

可再生能源发电主要依赖于自然界可再 生的清洁能源, 然而我们利用这些清洁能源 时, 不可避免地会面临这些自然的力量固有 的一些特点, 比如季节性、周期性、不稳定 性、随机性、昼夜差异性、能量密度较低等。 往往是用电负荷高的时候, 自然力却可能很 低 (如图 1); 又由于电能不能被大规模储存, 且要依托网络做到发输配售瞬时平衡, 因此 风能、太阳能等可再生能源大规模发电并网 一方面会对电网安全稳定运行产生影响; 另 一方面可再生能源大规模发电并网要求系统 具备较强的调峰能力, 带来系统投资和部分 电源运行成本的大幅度增加, 从而使社会用 电成本的增加 ${ }^{[12]}$ 。

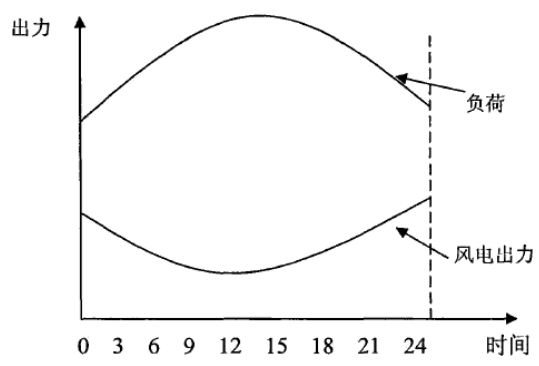

图 1 风电出力时差

可再生能源发电并网后, 电网不得不全 额高价收购其发电量, 并提供相应的并网配 套设施投资, 如风电和光伏发电的波动电源 特性使得电网企业不得不增加备用辅助服务 的购买以保证系统稳定可靠运行, 从而降低 了电网企业的购售电利润，增加了其投资成 本和辅助服务购买成本。常规火电企业往往 因系统中可再生能源发电量的优先调度而使 得常规发电机组的年利用小时数下降, 火电 机组发电效益随之下降; 另外为满足可再生 能源发电优先调度要求, 常规火电机组不得 不增加启停机次数来调峰, 从而常规火电企 业不仅遭受售电利润减少的影响, 而且增加 了机组的启停和检修费用。 


\section{3 可再生能源电力外部性解决办法}

针对可再生能源发电并网外部性问题, 可以从技术和经济层面来解决。可再生能源 发电并网过程中的技术外部性是指由于能源 属性、发电技术的不同对电力系统产生的谐 波污染、电能质量波动、闪变等影响电网可 靠运行的技术类问题。因此, 解决技术外部 性的主要措施是加大投资力度, 促进发电技 术进步，从而减少技术外部性的影响 [13]。

经济外部性方面, 目前主要采用征税或 补贴、政府直接干预、产权交易及法律诉讼 等四种方法。针对我国具体情况, 目前对可 再生能源电力发展的扶持主要采取相关补贴 以及税收等激励政策。

\section{3 可再生能源电力激励政策评价}

由上文可知, 可再生能源电力相比传统 能源电力, 在社会经济效益和环境效益等方 面有非常大的正外部性和优势, 但在电网安 全稳定运行和调度调峰等方面有其固有的负 外部性, 这种负外部性会增加电网运行维护 成本, 从而增加用户用电成本, 但是其正外 部性为我们节约大量环境成本。综合来看, 随着技术的提升, 可再生能源电力的正外部 性是大于负外部性的。这也是国家采取各种 激励政策来支持和鼓励可再生能源产业发展 的原因，而经济激励政策则是市场机制下促 进可再生能源电力发展的主要手段, 通常从 税收、补贴、融资、价格和产业等方面制定 针对可再生能源的政策优惠, 如我国目前的 贴息贷款制度、可再生能源发展专项资金制 度、可再生能源电价附加制度、税收优惠等。 在电力市场化脚步不断加快的今天，发 电、输电、配电、用户、甚至电网设备制造 商和政府之间会形成复杂的利益博弯关系 (进一步的研究结果将另文发表, 本文不再 赘述), 其博弯结果对可再生能源电力行业的 发展而言有着举足轻重的影响。另一方面, 各方博弯结果也会对政府政策的制定和完善 有一定的参考价值。总结起来, 通过对可再 生能源外部性的分析并考虑可再生能源电力 利益相关者之间的博恋, 下面对现有可再生 能源电力补贴政策有待完善之处进行评价并 提出建议。

\section{1 补贴和税收机制不完善}

欧美可再生能源电力强国的发电效率显 著优于我国, 除了其技术的先进, 很重要的 因素在于其大力的并网补贴的力度与税收优 惠政策。中国可再生能源发电相关政策推动 程度依然不足，经过了多年的不断论证，成 本分摊、利益分配格局仍然是阻碍新能源电 力顺利并网的重要因素。

\section{（一）可再生能源发电补贴不足}

我国已设立可再生能源发展基金对可再 生能源开发利用提供资金支持，发展基金包 括国家政府的专项基金和可再生能源电价附 加收入等。其中, 可再生能源电价附加收入 是目前补贴可再生能源上网发电的唯一资金 来源。随着可再生能源的迅速发展, 电价补 贴远跟不上可再生能源发电的发展速度, 电 价附加补贴缺口日趋增大。另外, 除了电价 附加征收标准造成的资金缺口问题，由于行 政程序圥余, 可再生能源电价补贴存在发放 滞后的现象。可再生能源电价附加补贴的不 足和发放延迟对可再生能源发电项目具有直 接的冲击, 极大地降低了投资者的投资热情, 不利于可再生能源发电的开发利用和技术进 步 ${ }^{[14]}$ 。只有当政府补贴能使自主研发的成本 降至低于技术引进的成本，企业才会考虑靠 自己的能力提高技术水平。因此, 必须考虑 增加补贴额度。

\section{（二）税收制度亟待完善}

当前的可再生能源产业发展水平上, 希 望以征收化石燃料税来达到促进发电公司选 择可再生能源发电的意愿很难实现, 或者说, 单单靠征收化石燃料税是不能实现促进发电 公司选择可再生能源发电的目的的, 尚需完 善税收制度，结合可再生能源电力技术、产 业发展水平，促使传统发电公司主动降低化 石燃料发电份额, 增加可再生能源发电份额。

\section{2 上网电价机制缺乏灵活性}

尽管目前的固定电价制度在可再生能源 电力发展初期, 为提高可再生能源发电的吸 引力和投资积极性，有效促进可再生能源发 电的装机容量增长发挥了重要作用, 但随着 可再生能源装机的迅速增长, 固定电价制度 也面临着一些挑战。以风电为例, 由于风能 
资源和电力负荷中心之间的分配不均衡, 需 要跨省电能交易, 将多余的风电外送, 促进 风电并网, 但是中国不同地区实行四种固定 风电标杆价格标准, 使得风电的跨省交易实 现起来较为困难与复杂。另外, 固定电价制 度使得市场上的可再生能源价格不能由市场 决定, 缺乏灵活性, 导致可再生能源发电不 能及时、有效地对负荷水平变化做出反应, 不利于可再生能源发电的大规模消纳, 同时, 固定电价对收益的保障阻碍了技术进步。迫 切需要诸如可再生能源配额制、可再生能源 证书交易等激励可再生能源发电的更加灵活 的市场化手段、政策的出台。

\section{4 结束语}

本文以可再生能源发电外部性为视角审 视现行价格补贴政策, 在指出所存在问题的 同时也提出了相应建议。然而, 可再生能源 发电技术多样，各类技术商业化发展程度不 一, 各国可再生能源资源禀赋条件千差万别, 经济发展水平和负担能力不同, 没有现成的 价格 (补贴) 机制能够照搬, 唯有从可再生 能源电力的成本、技术等因素的形成特性入 手, 深入研究可再生能源电力投资的微观过 程及决策特征, 结合我国电力市场特点及可 再生能源发展阶段探索出一条灵活有效的、 促进可再生能源电力发展目标实现的可再生 能源电价机制, 增强社会对可再生能源电力 的投融资信心，促进可再生能源电力发展。

\section{致谢}

本文为国家自然科学基金项目 （71473031）的阶段性成果之一。

\section{References}

[1] 赵子健, 赵旭. 可再生能源上网电价的 分摊机制研究 [J]. 科技管理研 究,2012,23:193-195.

[2] 杨帅. 我国可再生能源补贴政策的经济 影响与改进方向——以风电为例 $[\mathrm{J}]$. 云 南财经大学学报, 2013, 02: 64-74.

[3] 谢旭轩, 王仲颖, 高虎. 先进国家可再生 能源发展补贴政策动向及对我国的启示 [J]. 中国能源, 2013, 08: 15-19.
[4] 汪莹. 我国可再生能源产业的财政补贴 制度研究[D]. 西南政法大学, 2012.

[5] 柯建飞. 可再生能源经济激励机制研究 [D]. 福州大学, 2006.

[6] 赵寒娇. 关于我国可再生能源电力产业 发展的激励政策研究[D]. 浙江财经学院, 2010.

[7] HüseyinBenli. Potential of renewable energy in electrical energy production and sustainable energy development of Turkey: Performance and policies[J]. Renewable Energy, 2013,50:

[8] Cheuk Wing Lee,JinZhong. Top down strategy for renewable energy investment: Conceptual frame work and implementation[J].RenewableEnergy,2014 ,

[9]FlorianKern,AdrianSmith,ChrisShaw,RobRa ven,BramVerhees. From laggard to leader: Explaining offshore wind developments in the UK[J]. Energy Policy,2014,:

[10] Durmus Kaya. Renewable Energy Policies in Turkey[J]. Cogeneration \&amp; Distributed Generation Journal,2005,201:.

[11] RyanWiser,StevenPickle,Charles Goldman. Renewable energy policy and electricity restructuring: a California case study[J]. Energy Policy,1998,266:

[12] 戴杰超. 基于可再生能源发电并网外部 性的电价形成机制研究[D]. 华北电力大 学, 2014.

[13] 赵会茹,戴杰超. 基于协整分析法的我国 风电电价形成机制有效性检验 $[\mathrm{J}]$. 可再 生能源, 2013, 09: 69-73.

[14] 陆洲. 基于博弯论的中国风电并网问题 研究[D]. 兰州理工大学, 2013. 